\title{
O Lyra e o seu Kinetographo: exibições fílmicas no Recife ${ }^{1}$
}

\author{
Felipe Davson Pereira da Silva \\ Universidade Federal Fluminense, Programa de Pós-Graduação em Cinema e Audiovisual, Niterói, RJ, \\ Brasil \\ ORCID: https://orcid.org/0000-0003-1300-8071
}

\section{Alcileide Cabral do Nascimento}

Universidade Federal Rural de Pernambuco, Departamento de História, Recife, PE, Brasil

ORCID: https://orcid.org/0000-0002-3768-3357

\begin{abstract}
Resumo
O presente trabalho teve como objetivo analisar algumas exibições cinematográficas realizadas no Recife no final do século XIX. A partir de vestígios que permitiram compreender como ocorreram essas projeções e sua divulgação pela imprensa local. Esta pesquisa teve como um dos principais resultados o estudo sobre um dos pioneiros do cinema na cidade, Francisco Pereira de Lyra, que durante três meses, fez sessões pagas com o Kinetographo, em Recife.
\end{abstract}

\section{Palavras-chave}

Cinema. Kinetographo. Recife. Lyra. Imprensa.

\section{Introdução}

A historiografia do cinema em Pernambuco, mais precisamente, no Recife, é extensa e envolve pesquisas relacionadas majoritariamente em três momentos: o Ciclo do Recife ${ }^{2}$, datado de 1922 a 1931, o Super 8, ocorrido entre os anos 70 e 80 e o Cinema da Retomada 3 , a partir dos anos 90 . São pesquisas que se desdobram em vários pontos, desde produção, análises fílmicas, roteiro, direção de arte, dentre outros.

\footnotetext{
1 Versão ampliada de parte do terceiro capítulo da dissertação: SILVA, Felipe Davson Pereira da. Novidade, imaginário e sedentarização: o espetáculo cinematográfico no Recife (1896-1909). 2018. Dissertação (Mestrado em História) - Programa de Pós-Graduação em História, Universidade Federal Rural de Pernambuco, Recife, 2018.

2 Para mais informações sobre o Ciclo do Recife, consultar: FILHO, Paulo Carneiro da Cunha. A Utopia provinciana: Recife, cinema, melancolia. Recife: Ed. Universitária da UFPE, 2010.

${ }^{3}$ Para mais informações consultar: NOGUEIRA, Amanda. 0 novo ciclo de cinema em Pernambuco: a questão do estilo. Editora UFPE, 2010. NOGUEIRA, Amanda Mansur Custódio. A brodagem no cinema em Pernambuco. Tese (Doutorado em Comunicação) Programa de Pós-graduação em Comunicação. Universidade Federal Rural de Pernambuco. Recife, 2014.
} 
Um dos trabalhos precursores na divulgação e análise da história do cinema em Pernambuco teve início com a pesquisa de Lucilla Bernardet (1970), intitulada Cinema pernambucano de 1922 a 1931: primeira abordagem ${ }^{4}$. Prontamente, outros estudos surgiram para ampliar essa escrita histórica sobre a conhecida invenção moderna, o cinema, equipamento que surgiu no final do século XIX em diferentes lugares, mas que ganhou destaque na França com o cinematógrafo.

Se o cinema surgiu no final do século XIX e desembarcou no Brasil em 1896, por que a historiografia sobre o período do cinema silencioso no Recife se concentra, sobretudo a partir do Ciclo do Recife5? Pesquisas em outros estados brasileiros já apontam exibições e filmagens ocorridas em cidades como Rio de Janeiro, São Paulo, Porto Alegre, etc. No caso de Recife, buscamos a partir de novos trabalhos, ampliar tais investigações (SILVA, 2018).

Utilizaremos a imprensa local como fonte, devido a sua importância em registrar e trazer índicos de experiências urbanas do Recife, no momento em que ocorreram as exibições cinematográficas. Foram coletados 18 textos publicados em dois periódicos, o Diário de Pernambuco e o Jornal do Recife, ambos com grande circulação no período analisado, entre os dias 15 de agosto a 25 de dezembro de 1896.

Assim, este trabalho teve como objetivo investigar exibições fílmicas executadas no Recife, no final do século XIX. Nesse sentido, a pesquisa se debruçou sobre os meses iniciais das sessões públicas na cidade, pelo ator Francisco Pereira de Lyra, que também era um visionário e um empreendedor de um mercado de entretenimento que se ampliava com os equipamentos modernos.

\section{0 cinema: do Rio de Janeiro para outros estados}

Umas das possíveis primeiras projeções de filmes ocorridas no Brasil que se tem notícia data de julho de 1896, na capital federal da época, o Rio de Janeiro (ARAÚJO, 1985). Inicialmente apareceu com um nome diferente do conhecido cinematógrafo, o Omniographo, como se pode observar na notícia:

\footnotetext{
${ }^{4}$ Outros autores já haviam escrito sobre o Ciclo do Recife, mas de forma mais modesta. Como exemplo: VIANY, Alex. Introdução ao cinema brasileiro. Rio de Janeiro: Alhambra Embrafilme, 1987. Primeira edição datada de 1959.

${ }^{5}$ Já existem alguns trabalhos que se debruçam na investigação do período do cinema silencioso no Recife, a partir de 1900, como exemplo: ARAÚJO, Luciana Corrêa de. 0 cinema em Pernambuco (1900-1930). In: Fernão Pessoa Ramos; Sheila Schvarzman. (Org.). Nova História do Cinema Brasileiro. São Paulo: Edições Sesc, 2018, v. 1, p. 90-123.
} 
Com este nome tão hybridamente composto, inaugurou-se hontem às duas horas da tarde, em uma sala á Rua do Ouvidor, um apparelho que projecta sobre uma tela collocada ao fundo da sala diversos espetaculos e scenas animadas, por meio de uma serie enorme de photografias. Mas desenvolvido do que o kinetóscopio do qual é uma ampliação que tem a vantagem de offerecer a visão, não a um só espectador, mas a centenas de espectadores, cremos ser este o mesmo apparelho a que se dá o nome de cinematographo. (OMNIOGRAPHO, 9 jul. 1896, p. 3).

Nota-se a partir desta matéria e de outras que se seguiram por diversas regiões do país ${ }^{6}$, um tipo de descrição sobre essas exibições. Essas reportagens destacavam o nome do aparelho, seguido de suas funções técnicas (SOUZA, 2004). Além da admiração causada por quem via tais imagens em movimento, que fortalecia a ideia de um equipamento oriundo do mundo moderno, no qual o Brasil gostaria de se enquadrar. 0 cinema trouxe os "ares da modernidade" tão em voga.

As exibições ocorriam de forma itinerante, nesse cenário, as pessoas responsáveis pela gestão comercial alugavam espaços estratégicos, a fim de adquirir uma boa porcentagem dos lucros, e lá permaneciam por alguns meses ou sessões (ARAÚJO, 1981). Quando, diante de tal diversão, as admirações do público começavam a diminuir gradativamente e o dinheiro já não era suficiente, buscavam-se novos endereços para arrecadar mais.

Foi nesse período que diversas regiões do Brasil, rapidamente, com a ajuda dos transportes que existiam como trens, maxabombas e navios, conheceram o cinema silencioso. Desse modo, essas imagens em movimento deixaram de ser apenas notícias do jornal local para se transformarem em realidade. Segundo Trusz (2010), a fase da exibição itinerante criou condições que permitiram uma nova e crescente forma de envolvimento do público com o cinema, e este:

Surgiu como uma nova tecnologia de percepção, reprodução e representação e se tornaria uma mercadoria cultural de produção e consumo de massa. Ao longo deste processo, ele também se constituiu em um novo espaço de congregação social na esfera pública, o que ocorreu simultaneamente a sua caracterização e afirmação como novo gênero espetacular. (TRUSZ, 2010, p. 19).

\footnotetext{
${ }^{6}$ Pode-se citar alguns anúncios de jornais como: República. Santa Catarina, 7 nov. 1897, p. 3; Commercio do Amazonas, Amazonas. 24 nov. 1898, p. 1; A República. Paraná, 9 out. 1897, p. 3; A União. Paraíba, 4 set. 1897, p. 3.
} 
Esse alcance proporcionado pelos primeiros equipamentos cinematográficos, fez com que esse novo modelo de entretenimento no Brasil ganhasse um público crescente, o que possibilitou, em pouco tempo, a criação de salas específicas para exibições de filmes (DA-RIN, 2004). Essa diversão coletiva que, inicialmente, dividia o palco com outras atrações pôde, portanto, usufruir de um espaço exclusivo. Abaixo podemos observar a rápida disseminação do cinema em terras brasileiras:

Quadro 1 - Projeções cinematográficas pelo Brasil

\begin{tabular}{|c|c|}
\hline Rio de Janeiro & 1896 \\
\hline São Paulo & 1896 \\
\hline Porto Alegre & 1896 \\
\hline Recife & 1896 \\
\hline Belém & 1897 \\
\hline Paraíba & 1897 \\
\hline Manaus & 1897 \\
\hline Curitiba & 1897 \\
\hline Santa Catarina & 1897 \\
\hline Bahia & 1897 \\
\hline Minas Gerais & 1897 \\
\hline Bahia & 1897 \\
\hline São Luiz & 1898 \\
\hline Natal & 1898 \\
\hline Belo Horizonte & 1898 \\
\hline Aracaju & 1899 \\
\hline Teresina & 1901 \\
\hline Mato Grosso & 1903 \\
\hline & 189 \\
\hline
\end{tabular}

Fonte: Silva (2018).

Portanto, não demoraria muito para que o Recife tivesse um pioneiro no ramo do entretenimento cinematográfico: o ator Lyra com sua perspicácia para vislumbrar as possibilidades desse mercado. Iniciado no fim do século XIX, o cinema já mostrava a grande potência industrial que se consolidaria em poucos anos. 


\section{Lyra e o seu Kinetographo}

O escritor Jean-Claude Bernardet (1995), em seu livro Historiografia Clássica do Cinema Brasileiro, problematizou sobre os mitos e origens do cinema nacional. Segundo o autor, existem diferenças historiográficas entre o nascimento do cinema no Brasil e no estrangeiro. Ele dissertou que alguns teóricos, como George Sadoul, estabeleceram que o início do cinema se deu enquanto "uma exibição pública e paga, ou seja, o filme na tela diante de espectadores que pagaram ingressos para ter acesso à projeção" (BERNARDET, 1995, p. 25). Porém, na perspectiva de Souza (2004), o cinema nacional teria se originado com suas primeiras filmagens.

Segundo Bernardet (1995), isso não foi por acaso, pois se criou um discurso de cunho nacionalista acerca do cinema brasileiro, priorizando, enfaticamente, suas produções fílmicas e deixando em segundo plano o circuito exibidor. Esse discurso foi proferido e ampliado a partir dos anos 507, como forma de destacar uma busca histórica pela industrialização do cinema.

No caso de Recife, podemos inferir que o surgimento do cinema se deu pelo viés da exibição pública e paga, e não pela produção fílmica. Esta, apesar de ser importante, ficou em segundo plano e, neste sentido, como chama atenção Bernardet (1995), "o evento de exibição é o próprio acontecimento". Provavelmente, foi com a chegada de Lyra, da Europa, que os recifenses conheceram um aparelho cinematográfico nesta cidade. Mas quem foi Lyra?

Foi um ator cômico que começou sua carreira em meados dos anos 1870. Aos poucos foi ganhando notoriedade na arte de interpretar e conseguiu fama na cidade (FIGUEIRÔA, 2006). Dirigiu diversas peças, entre elas: Mundo, Diabo e Carne e O Diabrete Atraz da porta. Como descreve a matéria abaixo:

No Theatro Chalet, em Caxangá haverá hoje um bonito espetaculo, organisado pelo aplaudido actor Lyra. Sendo representadas as lindíssimas peças Mundo, Diabo e Carne e o Diabrete Atraz da porta. O Lyra, sempre incansavel em promover distracções aos habitantes daquelle pitoresco arrabalde e dos que alli vão passear, espera que o seu Theatro Chale rogorgite, como nas festas anteriores, de espectadores, e é isto o que desejamos suceda. Começará o espetaculo ás $6 \frac{1}{2} 2$ horas da tarde e

\footnotetext{
${ }^{7}$ Autores como Paulo Emilio Salles Gomes e Alex Viany foram alguns dos pensadores que propagaram esse discurso em prol das produções fílmicas no cinema brasileiro. Consultar: GOMES, Paulo Emílio Sales. Cinema: trajetória no subdesenvolvimento. 2. ed. São Paulo: Paz e Terra, 1996.; VIANY, Alex. Introdução ao cinema brasileiro. Rio de Janeiro: Alhambra Embrafilme, 1987.
} 
terminará ás $91 / 2$ da noute, afim de que possam os que vierem para o Recife, alcançar o trem de 9 e 40 minutos. (TEATROS E SALÕES, 12 jan. 1890, p. 3).

Como se evidencia nesta notícia, o ator Lyra, então proprietário do Teatro Chalé, apresentava diversos espetáculos, inclusive com atores locais e de outros estados, tendo também viajado pelo Brasil, aumentando sua fama como artista. Nota-se ainda, informações sobre o horário das peças, assim como o horário em que o trem passaria pela Caxangá, para que o público pudesse pegá-lo. 0 Lyra teve destaque com um carrossel, brinquedo com assentos geralmente em forma de animais que girava em torno de um eixo vertical, instalado no começo do século XX (SANT'ANNA, 1932, p. 3; ESDRAS-FARIAS, 1946, p. 6).

As diversões noturnas e a existência da iluminação das vias públicas possibilitaram o aumento das viagens pelos transportes. Com isto, um maior número de pessoas pode frequentar tais estabelecimentos e voltar para suas residências sem muitas dificuldades (ZAIDAN, 1991). A vida noturna do Recife ganhou, então, movimento de carros, pessoas, cortejos, boêmios, namoros, festas e diversões ao gosto do pagante.

Foi nesse clima de novidades que o Lyra tirou férias. Segundo consta no Jornal do Recife (EMBARQUE, 19 jul. 1896, p.3), viajou para a Europa em julho de 1896, onde buscou novos objetos para acrescentar nos seus espetáculos. Em uma nota no jornal da época, através de um telegrama, soube-se que:

Em regresso a este estado, sabe-se por telegramma. Tomou passagem em Pariz, a bordo do Chile o conhecido e activo actor Lyra. Traz um importante apparelho illusionista, desconhecido no Brazil, e que exhibirá em nossos theatros durante uma semana, seguindo depois para a capital federal e Montevidéo. (ACTOR LYRA, Recife, 25 ago. 1896, p. 2).

Ao regressar da Europa, Lyra tentou alugar o Teatro Santa Isabel para a estreia de seu mais novo espetáculo. Dada a importância desta iniciativa e da possível exibição cinematográfica na cidade, seu feito foi narrado com entusiasmo por um jornal da época:

Não tendo o sympathico Lyra conseguido estréar o seu Kinetographo no Theatro Santa Isabel, fará a estréa no edifico em que funccionou a Fabrica de Roupas, no largo da estação da Estrada de Ferro Central de Pernambuco, onde continuará a funccionar durante uma semana, devendo começar no próximo domingo. 0 publico que não deixe de ir apreciar esse apparelho, pois é elle uma verdadeira maravilha. (KINETOGRAPHO, 4 set. 1896, p. 3). 
A primeira coisa que se deve observar nesta reportagem é o título: Kinetographo, que destaca o nome do equipamento. Já não seria, portanto, um cinematógrafo dos Lumière, porque se constata que Lyra passou alguns dias em Paris e poderia ter comprado o equipamento nesta cidade. Assim pode ser visto em outra notícia:

\begin{abstract}
Sabe-se por telegrama particular ter tomado passagem no vapor francez Chili o estimado actor Lyra, que se achava em Pariz, onde fora adquirir um importante aparelho ilusionista e outras novidades do gênero das companhias americanas de variedades. Demorar-se-ha nesta Capital Federal e Rio da Prata. (EM VIAGEM, 25 ago. 1896, p. 2).
\end{abstract}

Thomas Edison, ao criar o kinetoscópio, precisava de um aparelho que produzisse os filmes, nomeou-o kinetograph por volta dos anos 1892 e 1893 (SKLAR, 1975). Segundo Mannoni (2003), no começo de 1896, uma máquina patenteada com o nome de Kinetograph de Bedts ${ }^{8}$ foi criada pelo francês George William de Bedts, um representante comercial dos americanos e, devido a sua proximidade com inventos tanto da França quanto dos EUA, explicaria a semelhança do nome do objeto de Edison. Isso geraria uma concorrência com o cinematógrafo dos Lumière. logo, tudo indica que seria esse dispositivo batizado de Kinetographo, no Recife, trazido por Lyra, que pesava em torno de $5 \mathrm{~kg}$, com tiras de filme de $35 \mathrm{~mm}$

Não foi possível descobrir o motivo que levou o Teatro Santa Isabel a não permitir a estreia de Lyra neste, mas ele conseguiu outro lugar para promover o seu espetáculo. Isto aconteceria, segundo documentos à época, em um prédio onde funcionou uma fábrica de roupas brancas localizada no Bairro de São José, $n^{\circ}$ 87, como concessão do governo, época em que várias fábricas de roupas e de tecidos estavam se instalando no Recife (COMPANHIA NACIONAL DE CAMISAS E ROUPAS BRANCAS, Recife, 13 set. 1894, p. 3). Outro ponto de destaque sobre esta localização é a Estação de Ferro Central de Pernambuco, inaugurada em 1885, onde embarcavam cidadãos com destino a Caruaru (MAIOR, 2010). A exibição ocorreria, mais precisamente, no largo dessa Estação.

\footnotetext{
${ }^{8}$ A câmera quinetógrafo era compacta (23,5 cm de altura, 16,5 cm de largura e 20,5 cm de comprimento) e pesava apenas 5 kg. 0 mecanismo de tração era inspirado no de Edison, com duas rodas dentadas dispositivas verticalmente, uma sobre a outra. A roda do alto, menor, tinha apenas três dentes em suas circunferências, que assim ficava dividida em três seções iguais. Um a um, os dentes penetravam em cada um dos dez grupos de dentes existentes na circunferência do segundo disco, cujo diâmetro era maior. Esta segunda roda girava de maneira intermitente, em tempos iguais de movimento e repouso, como resultado dos diferentes comprimentos de arco das seções das duas rodas. Esse mecanismo ligava-se a um dispositivo dentado de alimentação, que puxava o filme, e também ao obturador, que tinha duas aberturas (MANNONI, 2003, p. 440).
} 
O Jornal do Recife (KINETOGRAPHO, 4 set. 1896, p. 3) não menciona a Casa de Detenção, que se localizava ao lado da Praça Visconde de Mauá, perto da estação, o que indica que esse largo seria justamente o terreno menos habitado em paralelo aos trilhos ferroviários. A escolha de Lyra foi estratégica, pois o embarque e desembarque de passageiros era grande e, acredita-se que, na concepção do ator, o público para essa nova diversão estaria garantido.

Do dia 4 ao dia 13 de setembro poucas notícias referentes ao Lyra com o seu Kinetographo foram encontradas. Abaixo uma delas:

No próximo domingo o actor Lyra fará a exibição do Kinetographo. Tem sido muito trabalhorsa a montagem deste extraordinario invento de Edson, que esta destinado a causar admiração ao nosso publico. (O KINETOGRAPHO DO LYRA, 10 set. 1896, p. 4).

Ao organizar o local para a exibição da inauguração, o trabalho de montagem referido poderia ser em relação à distância correta do aparelho para a tela, da disposição das cadeiras, dentre outros problemas, por exemplo, elétricos. Vê-se, novamente, que se atribui a Thomas Edison a criação do Kinetographo, porém sem que haja certeza de ser utilizado um aparelho deste criador, assim como já problematizado anteriormente. No dia da inauguração, o Jornal do Recife não deixou de registrar e lembrar aos seus leitores da estreia naquela noite do dia 13:

No edificio da fabrica de Roupas, no Largo da Estação Caruarú, estréa hoje o Lyra, o symphatico e activo actor querido da platéa pernambucana, com o seu novo apparelho o Kinetographo trazido de Paris diretamente para Pernambuco. As sessões terão lugar de meia em meia hora, á começar das $61 / 2$ da tarde até a chegada do ultimo trem. Os pequenos intervallos serão preenchidos por uma orchestra. A entrada geral será para cada sessão de 1\$000. (ESTRÉA, 13 set. 1896, p. 3).

Observa-se, como anunciado anteriormente (SOUZA, 2004), que o destaque foi para o nome do equipamento, Kinetographo, além de dar ênfase ao local de onde veio a máquina: a França. A ideia de progresso era forte nos principais jornais da época, logo, algo vindo da Europa despertava interesse, pois o mundo "civilizado" estava introduzindo seus produtos e valores em terras distantes (ORTIZ, 1991), como na cidade do Recife.

0 ator Lyra, já bem conhecido pelo público, como ressalta o jornalista, teve espaço garantido na imprensa local. A quantidade de notícias sobre ele é bastante extensa, basta 
realizar uma busca pelo seu nome nos periódicos do final do século XIX e início do século XX para perceber o grande volume de reportagens ${ }^{9}$. Isso demonstra sua posição de destaque na cena cultural e social do Recife nesse período.

Percebe-se que o horário das sessões foi estabelecido por Lyra em função da chegada dos trens à Estação Central, nessa época conhecida como Estação de Recife a Caruaru ou Estação Caruaru (MAIOR 2010). Logo, foi pensado logisticamente o tempo de cada exibição e seu intervalo até a próxima exposição. Pelo relato jornalístico, a intenção do artista era estrear de forma eufórica, uma vez que os intervalos foram preenchidos por uma orquestra.

Na mesma matéria (ESTRÉA, 13 set. 1896, p. 3), percebemos que o preço dos ingressos para assistir a exibição era de mil réis. Ao se comparar brevemente preços de outros produtos nesse período, constata-se que o valor do bilhete não era exorbitante, ou seja, que não limitaria o acesso apenas aos mais abastados, enquanto um espetáculo no Teatro Santa Isabel custava, para cadeiras de 1a classe, por volta de 50 mil réis. Portanto, o valor de mil réis para um espetáculo de meia hora (ARRAIS, 2000) seria relativamente menos custoso.

Dessa forma, ocorreu a estreia do aparelho de Lyra, num local estrategicamente pensado e em horários apreciáveis para que os pagantes pudessem pegar o trem, bonde ou outras conduções para suas residências ao término da exibição. Mas, tais notícias são limitadas, pois não informam quais filmes passaram, como teria sido o funcionamento do Kinetographo, ou se foi bem apreciado pela plateia. Tais incertezas foram respondidas nos próximos relatos, como descrito no jornal abaixo:

Este novo apparelho electrico-illusionista foi exhibido pela primeira vez,
ante-hontem, em um dos salões da Fabrica de Roupas do Largo da Estação
de Caruarú. A concurrencia foi extraoedinariamente animada. Em cada
uma das sessões foram apresentadas seis diferentes quadros, alguns de
valor artístico e outros de gênero comico, sendo os mais bem recebidos os
denominados: Noite Terrivel, Chegada do Sud Express, Desenhista,
Jardineiro e Coroação de Rossiere. Estes foram appaludidos por
prolongadas salvas de palmas. O salão está preparado de modo artístico,
em fundo negro, tendo o apparelho collocado a entrada, em um biombo
d'onde faz com auxilio electrico as suas difficies evoluções. Em tela branca
distante cerca de 10 metros faz patente a photographia animada em
tamanho natural. E' sorpretendente ver-se o correr de uma scena viva,
comica ou não, com todos os movimentos, como se estivesse sendo
representada por figurantes. Em nada se assemelha o Kinetographo as

${ }^{9}$ Nos principais periódicos da época, quase que diariamente divulgavam notícias sobre o ator Lyra no período pesquisado. 
lanternas ou Sylphoramas, como muitos supõem. E' um apparelho novíssimo e anda não visto em Pernambuco e que ao tempo que deleita deixa bem firme o valor scientifico de seu autor. O Lyra, acreditamos, vai ter durante esta semana consecutivas enchentes. E' justo que assim succeda para compensação dos exforços que sabe empregar o ufanoso artista. No jardim do edifício desde hontem foi estabelecido um ligeiro buffet. Amanhã haverá nova função (KINETOGRAPHO, 15 set. 1896, p. 3).

Nota-se que a localização ganhou mais um referencial indicando que as exibições ocorriam em um dos salões de dentro da fábrica, próxima à estação. Provavelmente devido a este lugar ser bem movimentado, pois sugere que a concorrência para assistir ao espetáculo teria sido bem animada, indicando um bom lucro inicial ao Lyra.

Observa-se também o nome dos filmes, como A chegada do Sud Express, caminho percorrido por um trem que ligava Portugal e França, a partir da década de 1880. Destacase, ainda, o filme Coroação de Rossiere que, provavelmente, seria o Le Couronnement de larosière (1896), além de O Jardineiro, o que indica ser o L'Arroseur Arrosé (1896), Noite Terrível, ou Terrible Nuit (1896). O texto informa que foram apresentados, em cada sessão, seis filmes, pontuando na notícia apenas cinco, talvez os mais aclamados pela admiração e salva de palmas dos observadores.

Outro ponto interessante está na forma que o redator descreve a notícia ao nomear os tipos de película, tratando por quadros ${ }^{10}$ de valor artístico ou cômico, como, por exemplo, O Jardineiro, L'Arroseur Arrosé, Lumière, (1896), película de menos de um minuto, onde surgem dois atores: um senhor regando o jardim em um único plano, um jovem entra na cena pelo lado direito do observador e pisa na mangueira, parando a circulação da água e o senhor tenta entender o que aconteceu e olha através da mangueira. Nesse momento, o garoto tira o pé e a água volta a sair pela mangueira molhando o rosto do homem, que fica bravo e corre atrás dele até alcançá-lo e lhe dar umas boas palmadas. Os observadores jornalísticos descreveram esta película como de maior valor cômico.

Dando continuidade à análise da matéria, destacamos a descrição do funcionamento do Kinetographo. Pelas informações, deduzimos que se tratava de um aparelho cinematográfico e não de outros dispositivos ópticos como mencionou o jornalista quando disse que: "Em nada se assemelha o Kinetographo as lanternas ou Sylphoramas, como muitos supõem" (KINETOGRAPHO, Recife, 15 set. 1896, p.3), demonstrando haver

\footnotetext{
${ }^{10}$ Cenas, vistas animadas, imagens em movimento, fotografias vivias, fotografias animadas são alguns dos termos utilizados durante a fase do primeiro cinema que vai de 1895 a 1908. Mas se pode encontrar essas palavras mesmo em períodos posteriores até a utilização do termo "filmes".
} 
conhecimento desses dispositivos e de seu funcionamento. Observa-se aqui a riqueza com a qual descreve o ambiente preparado para a projeção:

O salão está preparado de modo artístico, em fundo negro, tendo o apparelho collocado a entrada, em um biombo d'onde faz com auxilio electrico as suas difficies evoluções. Em tela branca distante cerca de 10 metros faz patente a photographia animada em tamanho natural. (KINETOGRAPHO, 15 set. 1896, p. 3).

A descrição é típica das projeções, já que a distância que o aparelho ficava era em torno de dez metros para que a imagem fosse ampliada, com fundo negro e a sala escura para dar visibilidade às cenas, uma vez que as salas ou espaços adaptados onde eram colocados tais aparelhos cinematográficos seriam locais planos, não havendo ainda salas com declínio no piso para facilitar a visibilidade. Por fim, o relato jornalístico termina informando da novidade do objeto, ainda não visto em Pernambuco. Exalta o valor científico do produto, comum no final do século XIX, quando se tratava de inovações tecnológicas vistas como progresso da sociedade (ORTIZ, 1991).

Além de elogiar Lyra pela exibição e pela colocação de um Buffet para os espectadores, em virtude dos atrativos descritos, o relato considera que o público continuará grande no decorrer dos dias. Os vestígios deixados nos jornais evidenciam a importância dessas fontes para a história e para a problematização dos fatos. Pois:

Se considerarmos que a História é tudo aquilo que do passado chegou até o presente, serão os rastros, restos e vestígios que perduram no tempo em diversos suportes que se constituirão nas fontes a serem interpretadas para explicitar gestos e ações pretéritas. (BARBOSA, 2013, p. 8).

A produção de notícias veiculadas pela imprensa da cidade atingia um público de leitores letrados e analfabetos, através dos círculos de leitura onde os primeiros liam em voz alta para os demais. Assim, permitia-se que houvesse um consumo maior desses periódicos e das notícias importantes que deveriam circular pela cidade. Havia, portanto, "um desejo de que aqueles textos fossem de conhecimento mais amplo" (BARBOSA, 2013, p. 95). Dessa forma, visto a importância dos acontecimentos citados acima, as notícias sobre Lyra e seu Kinetographo não se limitaram ao Jornal do Recife, que fez uma ampla divulgação da estreia e dos detalhes do dia da inauguração. Outro periódico local, o Diário de Pernambuco, descreveu também sua versão da estreia de Lyra e de seu aparelho óptico: 
Pela primeira vez, funcionou ante-hontem, na Fabrica de Roupas, o Kinetographo, apparelho que o actor Lyra, trouxe da Europa ultimamente. A primeira sessão começou ás 61,2 horas da tarde, e terminou ás 7, seguiram-se as demais que foram igualmente de meia hora, cada uma, havendo em todas extraordinária concorrencia, de cavalheiros e senhoras. Assistimos a uma d'ellas, e parece-nos que a impressão produzida nos espectadores, foi bôa. (KINETOGRAPHO DO LYRA, 15 set. 1896, p. 3).

No Diário de Pernambuco, as informações se assemelham as do Jornal do Recife, no que se relaciona à concorrência para assistir as cenas animadas e o tempo de duração das sessões de meia hora. As apresentações tiveram início por volta das 18h30, ou seja, à noite, momento ideal devido à baixa iluminação e à escuridão na hora da exibição. Após alguns dias, o Diário de Pernambuco publica outra matéria sobre a diversão do Lyra:

O Lyra tem estado nestes últimos dias feliz com o seu kinetographo. 0 público tem concorrido de modo animador, sendo para admirar a bella sociedade que se tem reunido para assistir o desempenho daquelle tão maravilhoso quanto custoso aparelho. No sábado deu-nos o Lyra uma linda vista da bailarina que agradou sobremodo. Obitiveram também aplpausos as scenas do besouro, desenhista e passagem do regimento. Atendendo a pedidos ainda se demorará por algumas noites, a exhbição do alto invento de Edison. Aproveitem os que souberem apreciar um artístico trabalho. Pernambuco é o primeiro Estado brasileiro que conhece o Kinetographo. (O KINETOGRAPHO, 22 set. 1896, p. 3).

As informações do redator descrevem que Lyra recebeu bom público, inclusive, sendo solicitado para permanecer mais tempo com as exibições. Inicialmente, previa-se que ele pretendia ficar por volta de dez dias, mas foi constatado que permaneceu quase três meses. Outros filmes exibidos são citados como Besouro, Bailarina, Passagem do Regimento e Desenhista. Não foi possível localizar quais seriam os títulos originais, além de que, o proprietário do Kinetographo trouxe uma boa quantidade de películas para projetar, fazendo sessões com cenas diferentes, já numa perspectiva de movimento da programação para continuar atraindo um público novo.

Lyra não só trouxe o Kinetographo, mas também um aparelho intitulado Raio X, algo considerado novo para a época, originado de experiências científicas, que em pouco tempo se tornou aparelho de entretenimento. Chegou aqui Recife com a máquina de projetar imagens em movimento: 
Foi este o titulo que o Lyra deu a um novo interessante apparelho que pretende fazer estrear hoje, ás 7 horas da noite, na fabrica de roupas do Largo de Caruarú. Muito em uso em Paris é de acreditar que seja bem aceito pelo nosso publico pois é assaz divertido e impressionador. Com elle promete o Lyra na forma da -photographia através dos corpos opacosmostrar em 5 minutos o esqueleto completo de qualquer individuo que se prestar a entrar em um ataúde collocado em face do publico. As pessoas que tomarem entrada para a secção do morto vivo teem direito a três vistas do Kinetographo, aparelho que tão apreciado tem sido. Amanhã terá lugar a segunda exhibição, em duas sessões, uma ás 7 e outra ás 8 horas da noite. (RAIO X, 27 set. 1896, p. 2).

Assinalamos a expertise de Lyra em colocar a máquina de Raio X como uma nova parte do espetáculo. Novamente se pressupõe que a redação do jornal teria assistido ao funcionamento do Raio X antes que o público ou tenha recebido informações detalhadas sobre o seu funcionamento, possivelmente como forma de propagandear mais essa maquinaria vinda da Europa, de terras "civilizadas", atraindo assim seu consumidor.

Verifica-se que essa notícia do Jornal do Recife, (RAIO X, 27 SET. 1896, P.2), apresenta um caráter descritivo, pois narra o que foi visto, e sua mensagem denota uma experiência do que foi positivo, indicando, assim, que o público continue a presenciar o espaço onde se instalou Lyra, inclusive demarca os horários da segunda exibição do Raio X. Outro ponto de destaque da reportagem, no que se refere ao Kinetographo, é que as projeções ficariam em segundo plano, pois, ao assistir o Raio X, ao pagante seria concedido presenciar três sessões animadas.

As informações sobre Lyra e seu Kinetographo, englobando, mais tarde, o Raio X, aumentam em quantidade, sobretudo, de acordo com as linhas editoriais do Jornal do Recife e do Diário de Pernambuco, não sendo observada em outro periódico da época uma publicidade tão proveitosa para o ator. Em uma nova notícia sobre seu espetáculo, pelo tempo que o mesmo ficou instalado próximo à Estação Central, foi perceptível que a frequência do público era constante. Logo, novos filmes precisavam chegar, visto que, mudanças na atração eram normais para manter sua novidade:

Este sympathico artista avisa nos de que hoje, ás horas do costume, realizará na Fabrica de Roupas, uma sessão variada e de gosto, sendo que farão parte do programa três boas scenas de Kinetographo e o aplaudido raios $\mathrm{x}$. o resto, dis nos o corajoso emprezario é segredo. Deve terminar a sua temporada dentro de poucos dias mas não o fará sem realizar uma sessão especial, dedicada ás Exmas. famílias pernambucanas que tanto o têm auxiliado, na qual deverá exhibir novas e interessantes vistas do Kinetographo, que chegarão da Europa n'esses dois dias, por encommenda 
feita telegraphicamente. O Lyra acredita que o publico continuará a dispensar-lhe auxilio, visitando o seu improvisado theatrinho que é actualmente o ponto onde todas as noites se reunem as mais distinctas famílias de nossa sociedade. (O LYRA, 9 out. 1896, p. 3).

Segundo a matéria acima citada, algumas informações são semelhantes e meramente descritivas, como as anteriores. Mantém-se o local da exibição, tanto do Kinetographo, quanto do Raio X, o público ainda frequentava com assiduidade e o valor do bilhete não foi mais divulgado. A manchete ao dizer que chegariam dentro de dois dias novos rolos, vindos da Europa, mais uma vez endossa o prognóstico dado de que os filmes exibidos nesse primeiro momento seriam, provável e majoritariamente, películas francesas. Assim descreve o Jornal do Recife:

Agradaram ao pessoal escolhido que compareceu ante-hontem no Kinetographo, as vistas ultimamente chegadas de Paris. A nosso vêr das exhibidas as mais importantes são as que representam as scenas do Mercado das Couves, Chegada do Czar e Sússú me deixe, que é interessante e comica. Esta ultima sabemos, será exhibida ainda hoje e a pedido. Pela primeira ves será apresentada a scena Duélo do amor. Esta é a ultima semana de trabalhos. (KINETOGRAPHO, 1 dez. 1896, p. 2).

Portanto, o comércio das películas vindas da França continuou enquanto Lyra esteve no bairro de São José, alguns filmes como Mercado das Couves, Chegada do Czar e Sússú me deixe, são citados, ambos com boa recepção. Das três obras cinematográficas, possivelmente, o filme Chegada do Czar seria o Cortège du Tzar allant à Versailles ou Cortège du Tzar au Bois de Boulogne (Georges Méliès, Star Film Company, 1896). A matéria demonstra que existiam outros filmes, como Duelo de Amor (KINETOGRAPHO, 1 dez. 1896, p. 2), mas de cunho implícito, além de opinar sobre os melhores da noite, dos quais alguns membros do Jornal do Recife assistiram.

Após a primeira exibição pública e paga do Kinetographo, no dia 13 de setembro de 1896, várias reportagens foram feitas sobre o seu realizador, Lyra, ressaltando seu novo espetáculo e empreendimento com equipamentos oriundos da Europa. Passados quase três meses, então, o Kinetographo estava dando o seu adeus às terras recifenses, algo comum nesse período, pois, segundo Calil (1996), ainda não havia salas próprias para exibição de filmes. Logo, o tempo de projeção era limitado, além de outros fatores, já que no caso de Lyra e de outros que depois trabalharam com o cinema, utilizavam-se deste como complemento em suas atividades. Pois, segundo Bernardet: 
Talvez não tenham sido homens de cinema, e sim homens de espetáculo, para quem o cinema foi um momento, uma oportunidade, não a base de seu negócio, a qual teria disso o espetáculo, incluindo o cinema entre outras possibilidades. (BERNARDET, 1995, p. 106).

Por fim, após meses próximo à Estação Central, a exibição proporcionada por Lyra chegou ao seu fim com a repetição de alguns filmes e se pode supor que o público teria apreciado por tais películas, para que ele reproduzisse novamente nos últimos dias do seu divertimento, ou foi o caso de haver terminado o seu estoque de filmes. Na edição do Jornal do Recife, datada do dia 5 de dezembro de 1896, a manchete ressalta as últimas noites do espetáculo cinematográfico:

Hoje e amanhã serão as ultimas noutes de exhibições do Kinetographo. Entre outras vistas de gosto serão apresentadas as muito bem aceitas Sussú Bezouro e Duello de amor. Não devem faltar os que ainda não visitaram o atelier do Lyra, no oitão da estação de Caruarú. 0 Kinetographo é um apparelho digno de ser visto. (ULTIMAS NOUTES, 5 dez. 1896, p. 2).

Após essa pequena estadia do Kinetographo ao lado da Estação Central, chegou ao fim o espetáculo proporcionado por esse aparelho fílmico, juntamente com o anúncio da distribuição de prêmios para o público espectador, sugerindo que o espetáculo seria em outro local, mas, não conseguimos maiores indicações sobre isso. Segue abaixo:

\begin{abstract}
Amanhã e domingo, os frequentadores do Kinetographo terão direito a bilhetes numerados para distribuição, em cada noite, de cinco interessantes prêmios. São as duas ultimas noites em que fuccionará o Kinetographo Acha-se elle estabelecido presentemente no grande armazém junto ao antigo Quartel de Bombeiros. (PREMIOS, 25 dez. 1896, p. 2).
\end{abstract}

A pesquisa buscou mais informações de novas apresentações de Lyra com o Kinetographo, porém, após essas datas não foram visualizadas mais notícias do artista com tal equipamento. Devido à fama que tinha na cidade do Recife, logo surgiriam nos jornais novas informações de espetáculos teatrais de sua autoria11. Infelizmente não foi possível descobrir o que aconteceu com o aparelho e o porquê dele ter deixado de fazer novas apresentações e voltar para as peças teatrais.

\footnotetext{
${ }^{11}$ Como exemplo, estaria no bairro da Várzea para uma apresentação teatral (JORNAL DO RECIFE, 31 dez 1896, p. 3) e alguns dias depois em Olinda para mais apresentações. (JORNAL DO RECIFE, Recife, 4 abr. 1897, p. 3).
} 
Mas, o ator Lyra com o tempo, deixou de trabalhar com diversões e acabou ocupando-se como funcionário de um cemitério público, o cemitério de Santo Amaro, vindo a falecer em 1941 (SANT'ANNA, 1932, p. 3). Sendo um dos pioneiros em exibições cinematográficas em Recife e figura importante no cenário teatral no final do século XIX, ajudou a proporcionar novas formas de diversão nessa cidade.

\section{Considerações Finais}

0 presente trabalho teve como objetivo central analisar como ocorreram as exibições fílmicas na cidade do Recife, no final do século XIX, alguns meses após a criação e popularização de tais equipamentos no mundo. Para isso, foi necessário observar a chegada do cinema no Brasil e sua rápida expansão pelas diversas regiões do país.

Para investigar a inserção dos aparelhos cinematográficos, buscou-se como fonte primária os jornais da época, com destaque para o Diário de Pernambuco e o Jornal do Recife, periódicos de grande circulação durante o período estudado e que proporcionaram, a partir de uma análise documental, responder algumas lacunas referentes às sessões ocorridas no Recife, no período silencioso.

Pesquisamos informações relevantes sobre Francisco Pereira de Lyra, mas não foi possível localizar muitas referências relacionadas à sua vida, além do que foi encontrado nos jornais citados acima. Porém, foi de suma importância localizar registros sobre ele, visto que, com os relatos jornalísticos conseguimos chegar ao dia 13 de setembro de 1896, sessão paga e pública de um aparelho cinematográfico no Recife, mais precisamente no bairro de São José.

Assim, conseguimos acompanhar os passos de Lyra, por volta de três meses, onde ficou instalado seu espetáculo, próximo à estação ferroviária, valor do ingresso, quais películas teria passado, como se dava a troca para novos filmes vindos da Europa, sobretudo, da França, dentre outros detalhes descritos nos periódicos abordados.

Em suma, este trabalho procurou preencher lacunas sobre a historiografia do cinema em Recife, com ênfase no período silencioso. Esperamos que novos(as) pesquisadores(as) possam se debruçar sobre tal tema e ampliem o que já foi encontrado, desenvolvendo novos trabalhos a fim de fomentar ainda mais a importância histórica que o cinema representa em nossas vidas e nas memórias da cidade onde foi introduzido. 


\section{Referências}

ARAÚJO, Vicente de Paula. A Bela época do cinema brasileiro. São Paulo: Editora Perspectiva, 1985.

ARAÚJO, Vicente de Paula. Salões, circos e salas de cinema de São Paulo. São Paulo: Perspectiva, 1981.

ARRAIS, Isabel Concessa. Teatro de Santa Isabel. Recife: Fundação do Recife, 2000.

BARBOSA, Marialva. História da comunicação no Brasil. Rio de janeiro: Editora Vozes, 2013.

BERNARDET, Lucilla Ribeiro. 0 Cinema pernambucano de 1922 a 1931: primeira abordagem. São Paulo: Papirus, 1970.

BERNARDET, Jean Claude. Historiografia clássica do cinema brasileiro: metodologia e pedagogia. São Paulo, ANNABLUME, 1995.

CALIL, Carlos Augusto. Cinema e indústria. In: XAVIER, I. (Org.). 0 Cinema no século. Rio de Janeiro: Imago, 1996. cap. 2, p. 45-69.

CORTÈGE du Tzar allant à Versailles. Direção de Gerges Méliès. França: Star Film Company, 1896.

CORTÈGE du Tzar au Bois de Boulogne. Direção de Gerges Méliès. França: Star Film Company, 1896.

DA-RIN, Silvio. Espelho partido. Rio de Janeiro: Azougue Editorial, 2004.

ESDRAS-FARIAS. As diversões populares do Recife de ontem. Jornal Pequeno, Recife, 26 jan. 1946, p. 6.

FIGUEIRÔA, Alexandre. História do teatro em Pernambuco. Recife: Assembleia Legislativa do Estado de Pernambuco, 2006.

FILHO, Paulo Carneiro da Cunha. A Utopia provinciana: Recife, cinema, melancolia. Recife: Ed. Universitária da UFPE, 2010.

L' ARROSEUR Arrosé. Direção de Louis Lumière, França, 1896.

LE COURONNEMENT de larosière. Direção de Georges Méliès. França: Star Film Company, 1896.

MAIOR, Paulo Martin Souto. Nos caminhos do ferro: construções e manufaturas no Recife (1830-1920). Recife: CEPE, 2010. 
MANNONI, Laurent. A grande arte da luz e da sombra. Arqueologia do cinema. São Paulo. Ed Unesp, 2003.

ORTIZ, Renato. Cultura e modernidade: a França no século XIX. São Paulo: Editora brasiliense, 1991.

SANT’ANNA, Cyrillo de. História antiga. Jornal Pequeno, Recife, 27 ago. 1932, p. 3.

SILVA, Felipe Davson Pereira da. Novidade, imaginário e sedentarização: o espetáculo cinematográfico no Recife (1896-1909). 2018. Dissertação (Mestrado em História)Programa de Pós-Graduação em História, Universidade Federal Rural de Pernambuco, Recife, 2018.

SKLAR, R. História social do cinema americano. São Paulo: Editora Cultrix, 1975. SOUZA, José Inácio de Melo. Imagens do passado. São Paulo e Rio de Janeiro nos Primórdios do Cinema. São Paulo: Ed. Senac, 2004.

TERRIBLE Nuit. Direção de Georges Méliès, Star Film Company, 1896.

TRUSZ, Alice. Entre lanternas mágicas e cinematógrafos: as origens do espetáculo cinematográfico em Porto Alegre 1861-1908. São Paulo: Ecofalante, 2010.

ZAIDAN, Noemia. O Recife nos trilhos dos bondes de burro 1871-1914. 1991. 161 p. Dissertação (Mestrado em Desenvolvimento Urbano) - Centro de Artes e Comunicação, Universidade Federal de Pernambuco, Recife.

Jornais

ACTOR Lyra. Diário de Pernambuco, Recife, 25 ago. 1896.

COMPANHIA Nacional de camisas e roupas brancas. Diário de Pernambuco, Recife, 13 set. 1894, p. 3.

EMBARQUE. Jornal do Recife, Recife, 19 jul. 1896, p. 3.

EM VIAGEM. Jornal do Recife, Recife, 25 ago. 1896, p. 2.

ESTRÉA. Jornal do Recife, Recife, 13 set. 1896, p. 3.

KINETOGRAPHO do Lyra. Diário de Pernambuco, Recife, 15 set. 1896, p. 3.

KINETOGRAPHO. Jornal do Recife, Recife, 4 set. 1896, p. 3.

KINETOGRAPHO. Jornal do Recife, Recife, 1 dez. 1896, p. 2.

KINETOGRAPHO. Jornal do Recife, Recife, 15 set. 1896, p. 3.

O KINETOGRAPHO do Lyra. Diário de Pernambuco, Recife, 10 set. 1896, p. 4.

O KINETOGRAPHO do Lyra. Diário de Pernambuco, Recife, 13 set. 1896, p. 3. 
O KINETOGRAPHO. Jornal do Recife, Recife, 22 set. 1896, p. 3.

O LYRA. Jornal do Recife, Recife, 9 out. 1896, p. 3.

OMNIOGRAPHO. Jornal do Commercio, Rio de Janeiro, 9 jul. 1896, p. 3.

PREMIOS. Jornal do Recife, Recife, 25 dez. 1896, p. 2.

RAIOS X. Jornal do Recife, Recife, 27 set. 1896, p. 2.

TEATROS e Salões. Jornal do Recife, Recife, 12 jan. 1890, p. 3.

ULTIMAS noutes. Jornal do Recife, Recife, 5 dez. 1896, p. 2.

\title{
The Lyra and its Kinetographo: the first film exhibitions in Recife
}

\begin{abstract}
The objective of the present study is to analyze some cinematographic exhibitions in Recife at the end of the 19th century. This was done through an analysis of sources that provide an understanding of how the exhibitions occurred and how they were publicized in the local media. One of the main results of the paper is a study of a pioneer in the city's cinema, Francisco Pereira de Lyra, who for three months held paid exhibitions with a kinetograph in Recife.
\end{abstract}

\section{Keywords}

Cinema. Kinetograph. Recife. Lyra. Local media.

\section{Autoria para correspondência}

Felipe Davson Pereira da Silva

felipedavson@hotmail.com

\section{Como citar}

SILVA, Felipe Davson Pereira da; NASCIMENTO, Alcileide Cabral do. O Lyra e o seu Kinetographo: exibições fílmicas no Recife. Intexto, Porto Alegre, n. 52, e-90333, jan./dez. 2021.

DOI: http://dx.doi.org/10.19132/1807-8583202152.90333 
(c) (1) (\$)

BY NC 